\title{
LA MISE EN SCÈNE DEL PROYECTO SALESIANO EN EL SURORIENTE ECUATORIANO. LA EXPOSICIÓN ETNOGRÁFICA DEL ORIENTE (GUAYAQUIL, 1924) Y LA EXPOSICIÓN MISIONAL SALESIANA (TURÍN, 1926)*
}

\author{
POR \\ CHIARA PAGNOTTA ${ }^{1}$ \\ Taller de Estudios e Investigaciones Andino-Amazónicos, Universidad de Barcelona
}

\begin{abstract}
RESUMEN
Desde 1893, los salesianos fueron los encargados de desarrollar la obra misionera en el vicariato apostólico de Méndez y Gualaquiza, en la Amazonía ecuatoriana, donde vivía la población shuar. El objetivo de este trabajo es mostrar cómo las exposiciones salesianas de Guayaquil y Turín se convirtieron en exhibiciones públicas de los logros alcanzados en el territorio amazónico, y entre sus habitantes, por parte de los salesianos, destacando además las diferencias que emergieron de las dos exposiciones. Las fuentes utilizadas provienen del Archivio Salesiano Centrale en Roma (Italia), del Archivo Documental y Fotográfico Salesiano de Quito (Ecuador), de los artículos publicados en el Bollettino Salesiano, de unos periódicos de la época: El Telégrafo y El Universo, de Guayaquil, y La Stampa, de Turín.
\end{abstract}

PALABRAS CLAVE: salesianos; exposiciones misionales; Oriente ecuatoriano; representaciones; evangelización; civilización.

\section{THE MISE EN SCÈNE OF THE SALESIAN PROJECT IN THE ECUADORIAN SOUTH- EAST. THE ETHNOGRAPHIC EXHIBITION OF THE EAST (GUAYAQUIL, 1924) AND THE SALESIAN MISSIONARY EXHIBITION (TURIN, 1926)}

\begin{abstract}
Since 1893 the Salesians were in charge of developing their missionary work in the Apostolic Vicariate of Méndez and Gualaquiza, in the Ecuadorian Amazon, where the Shuar people was living. The aim of this work is to show how the Salesian exhibitions of Guayaquil and Turin became public exhibitions, of the achievements obtained in the Amazonian territory and among its inhabitants by the Salesians, also highlighting the differences that emerged from the two expositions. The sources come from the Archivio Salesiano Centrale in Rome (Italy), the Archivo Documental y Fotográfico Salesiano in Quito (Ecuador), the articles published in the Bollettino Salesiano, and from some newspapers of the time: El Telégrafo and El Universo of Guayaquil and La Stampa of Torino.
\end{abstract}

KEY WORDS: Salesians; missionary exhibitions; Ecuadorian East; representations; evangelization; Civilization.

Cómo CITAR este artículo / Citation: Pagnotta, Chiara. 2019. «La mise en scène del proyecto salesiano en el suroriente ecuatoriano. La Exposición etnográfica del Oriente (Guayaquil, 1924) y la Exposición Misional Salesiana (Turín, 1926)». Hispania Sacra 71, 144: 669-681. https://doi.org/10.3989/hs.2019.048

$\begin{array}{ll}\text { Recibido/Received } & 11-05-2018 \\ \text { Aceptado/Accepted } & 18-12-2018\end{array}$

* Este artículo es uno de los resultados de mi participación en el proyecto de investigación l+D+i HAR2015-64891-P (MINECO/FEDER, UE). A los evaluadores anónimos, mi agradecimiento por los comentarios y las sugerencias.

1 cpagnotta@gmail.com / ORCID iD: https://orcid.org/0000-0002-9810-3109 


\section{INTRODUCCIÓN}

A finales del siglo XIX, el mundo católico empezó a desarrollar lo que sería un creciente interés por las exposiciones que acontecían en la Europa de aquel entonces. Tras la Exposición de Londres, en 1851, habían tenido lugar varias exposiciones nacionales e internacionales que se habían convertido en un espacio de representación del desarrollo económico y productivo alcanzado por los diferentes países, y que resultaban útiles a la búsqueda de nuevos mercados para las producciones nacionales (López Ocón 1998).

Sabemos que, a lo largo del siglo XIX, se perfeccionaron herramientas de conocimiento y de poder - tales como el censo, el mapa y el museo-, útiles para la clasificación de las poblaciones colonizadas, y para representar la manera en que eran percibidas por los colonizadores (Anderson 1983). En este sentido, exhibir los objetos en una exposición significaba organizar los materiales de acuerdo a un orden estructurado por parte de los organizadores de la muestra. Por ende, las exposiciones se convirtieron en el lugar en el que mostrar los proyectos modernizadores y progresistas de los gobiernos y de sus élites ante sus propios países y habitantes (García Jordán 2015). Las exhibiciones, yendo más allá de Kipling (cit. en Burke 2001: 123), parecen haber sido el lugar en el que Oriente y Occidente se encontraron, siendo considerado el Occidente como el lugar de la civilización, y el Oriente como el de 'los otros'. Cabe subrayar, por tanto, que estas exposiciones fueron el lugar de exhibición y legitimación de las teorías evolucionistas de la época, del racismo científico y de la alteridad exótica. Concuerdo con Muratorio (1994a: 17) cuando propone que aquellas además sirvieron para que las élites desplegaran su iconografía del 'indígena' y del nacionalismo, y en que «reflejaban el universo de representaciones vigentes en la sociedad de esa época». El mundo católico y protestante también se interesó en ellas, dando lugar a peculiares formas de etnoexposiciones de carácter religioso. Sánchez Gómez (2011: 56) pone de relieve cómo la Iglesia católica, a diferencia de las protestantes, tempranamente rechazó la participación en las exposiciones universales de la época pues «esos espectáculos se muestran ante el visitante, ante el creyente, como auténticos paraísos terrenales, lo que supuestamente socavaría los propios cimientos de la fe»; además, de otro lado, las exposiciones parecían reticentes a incluir un espacio religioso en ella. Solo en 1890 se empieza a verificar la presencia en las exposiciones de algunas misiones católicas y esto culmina en la Exposición italoamericana de Génova en 1892, en donde, por primera vez en un contexto católico, son exhibidos unos cuantos nativos (dos adultos y seis niños fueguinos y araucanos). ${ }^{2}$

Finalmente, en 1925 tuvo lugar la gran Exposición Misional Vaticana (diciembre 1924-enero 1926). El salesiano y doctor en Ciencias Naturales Carlo Crespi había ido recuperando, desde 1923, para exhibirlos en ella, varios objetos procedentes del vicariato apostólico de Méndez y Gualaquiza (Ecuador), donde vivía parte de la población shuar. ${ }^{3}$ Antes de ser enviados al Vaticano, los hallazgos fue-

\footnotetext{
2 Para un análisis más exhaustivo al respecto, véase Sánchez Gómez (2013).

3 Los shuar de Ecuador están actualmente asentados en parte del territorio de la provincia de Pastaza, Morona Santiago y Zamora
}

ron mostrados en una Exposición etnográfica del Oriente, que tuvo lugar en Guayaquil, bajo la dirección del mismo padre salesiano. ${ }^{4}$ Posteriormente, en 1926, parte de los objetos fueron exhibidos también en la Exposición misional que la congregación salesiana organizó en la ciudad de Turín (lugar de fundación de la misma), con ocasión de las celebraciones por los 50 años del establecimiento de las misiones salesianas (cuyo aniversario había tenido lugar en 1925, y cuya celebración se había retrasado a causa de la coincidencia con las celebraciones del año jubilar en el Vaticano).

Para estudiar las exposiciones objeto de este ensayo, utilizamos el concepto de representación en el sentido indicado por Chartier (1989) y Marin (1993). Así, la representación es la materialización de las concepciones culturales del momento, y a la vez el efecto de la presencia de un objeto ausente sustituido por una imagen capaz de representarlo adecuadamente. Conforme a lo afirmado por Muratorio (1992: 21-22), en la Amazonía ecuatoriana del siglo XIX existía todavía un modo de ver, concebir y representar a los pueblos indígenas según sus grados de civilización, y esto situaba a los shuar que vivían en el territorio amazónico como máximos representantes de los pueblos 'salvajes', o no sumisos. Por ende, el ver y el representar aparecen en ese texto como actos materiales en la medida en que construyen medios de intervención en el mundo, y sitúan una hegemonía entre quien primero ve y luego representa, y el sujeto de la mirada. Precisamente en este sentido concuerdo con Poole (1997), que introduce, además, el concepto de economía visual para resaltar el conjunto de conexiones entre el hecho de ver y las relaciones sociales, desigualdades y poder, entre otros.

El objetivo de este trabajo es analizar cómo estas exposiciones se convirtieron en exhibiciones públicas de un proceso que se quería destacar a nivel nacional e internacional. Por un lado, interesa ver de qué manera los objetos recogidos por los salesianos fueron primero exhibidos en 1924 para un público nacional -en particular, la élite liberal, comercial y empresarial de Guayaquil, principal centro económico del país-, con el objetivo de dar a conocer al público ecuatoriano el territorio oriental de su propio país, y garantizar así el apoyo de los empresarios. Este apoyo se buscaba primero respecto al proyecto de civilización de dicha zona,

Chinchipe. Para un análisis etnohistórico sobre los shuar véanse, entre otros, los trabajos de Karsten (1935) y Taylor (1994a, 1994b). Hay que señalar que, conforme al lenguaje de la época tratada, a veces se utilizará el término jíbaros para referirnos al grupo, aunque ese término tiene una connotación negativa ligada a la conquista española. Acerca de la Exposición Misional Vaticana y las representaciones del Oriente ecuatoriano que tuvieron lugar en aquella ocasión, véase Pagnotta 2018.

4 Utilizamos 'Oriente' para referirnos a los territorios amazónicos de Ecuador, ya que este término concuerda con el lenguaje de la época, y se encuentra utilizado en los textos de los salesianos con los que hemos trabajado. La zona empieza a mencionarse como Amazonia solo a raíz de la guerra de 1941. De otro lado, cabe subrayar que, por lo que concierne la administración estatal, la provincia de Oriente fue creada por García Moreno en 1861 (abarcando un territorio mucho más amplio de las actuales provincias amazónicas) y fue disuelta en 1920. La Ley de Oriente de 1920 estableció la primera subdivisión territorial del Oriente ecuatoriano en dos provincias: la de Napo-Pastaza, en el norte, y la de Santiago-Zamora, en el sur. Esta última era la zona del Vicariato Apostólico encargado a los salesianos. Aquella ley fue acompañada de la creación de la Dirección General de Oriente. Véase más adelante en este mismo artículo. 
haciéndola devenir objeto de sus intereses económicos, y secundariamente respecto a su evangelización por medio de la educación en el trabajo 'productivo'. Por otro lado, pretendo poner en evidencia que estos intereses locales jugaron un papel a nivel internacional, cuando los mismos objetos fueron exhibidos en la exposición salesiana de Turín en 1926. Debo destacar que enfoco mi interés en estas dos exposiciones porque fueron organizadas únicamente por la congregación salesiana. En ellas emerge sin duda el papel del padre Crespi, científico y organizador (o co-organizador) de las exposiciones, como recolector de material, y ahí destaca con más claridad el proyecto de la congregación. ${ }^{5}$

Este artículo se sustenta en el análisis de una serie de documentos ubicados en el Archivio Salesiano Centrale en Roma (Italia), en el Archivo Documental y Fotográfico Salesiano de Quito (Ecuador), en los artículos y en la correspondencia de los misioneros publicada en el Bollettino Salesiano, y en los artículos de la prensa de la época de las ciudades de Guayaquil (El Telégrafo y El Universo) y de Turín (La Stampa).

En consecuencia, en un primer apartado se abordarán algunas consideraciones preliminares sobre el contexto histórico en el que se produjeron las imágenes exhibidas en las dos exposiciones para, en un segundo apartado, tratar los aspectos más relevantes respecto al territorio ecuatoriano y la recogida de los objetos. En un tercer apartado se examinará la Exposición Etnográfica del Oriente que tuvo lugar en la ciudad de Guayaquil, y en el cuarto se esbozarán algunos aspectos de la Exposición Misional Salesiana de la ciudad de Turín. Finalmente, en las conclusiones se ofrecerán algunas consideraciones a partir del estudio desarrollado.

\section{EL CONTEXTO DE LA PRODUCCIÓN DE IMÁGENES}

En el siglo XIX, Gualaquiza había sido un pueblo habitado por colonos que trabajaban en los entables, es decir, las grandes fincas en las que se cultivaba principalmente caña de azúcar, se recolectaba paja toquilla y cascarilla, y cuyos propietarios eran los principales terratenientes de la provincia de Azuay, cuya capital es la ciudad de Cuenca. El frente colonizador de la zona amazónica, cuyo protagonista fue la élite azuaya, se instaló precisamente en dichos entables. Hay que matizar que a mediados de siglo se había producido un repliegue de la colonización considerable, debido a la resistencia ejercida por parte de los shuar (Esvertit Cobes 2008: 49-56). Luego, hacia finales del siglo, la reactivación económica de la zona motivó a los terratenientes azuayos a dirigir sus intereses a abrir nuevos núcleos de colonización en Indanza y Méndez.

Cabe destacar que, desde 1893, los padres salesianos estaban desarrollando su obra misionera en el vicariato apostólico de Méndez y Gualaquiza (Pagnotta 2015). Desde el primer momento describían a los shuar «sentados en la oscuridad de la muerte esperan del Misionero [...] la luz evangélica y la verdadera civilización» (Mattana 1897: 312). Los salesianos habían optado por instalarse en Gualaquiza,

Los objetos recuperados fueron expuestos además en la Exposición Misional Vaticana, pero en esa el papel jugado por los salesianos estuvo muy diluido y por tal razón no es tratado en este texto, aunque sí en otro de la autora (Pagnotta 2018). en medio de un área en buena parte desconocida. Los primeros años de la misión estuvieron tan marcados por las dificultades para implementar el proyecto salesiano, que se llegó a afirmar por parte de Monseñor Costamagna - primer vicario apostólico-que «la misión entre los jíbaros es, sin lugar a dudas, la más difícil del mundo católico» («Da Gualaceo a Santiago di Méndez» 1920: 98).

La mayoría de los pobladores eran shuar, siendo los colonos blancos y mestizos netamente inferiores en número. ${ }^{6}$ Los salesianos procedieron a la construcción de una casamisión, en la que instalaron sendos talleres de carpintería y herrería, y también una escuela para niñas. Estos primeros años se caracterizaron por la escasez de recursos económicos de los salesianos, el aislamiento, y la sensación de hacer un trabajo en vano.

Durante los gobiernos liberales (1895-1925), el control de la región amazónica se convirtió en ingrediente fundamental del proyecto político de construcción de la nación ecuatoriana, y los misioneros salesianos se convirtieron en actores importantes en el desarrollo del proceso de evangelización y civilización del Oriente ecuatoriano.

Por parte de los salesianos, el proyecto misional se basaba en la educación en la fe religiosa y en el trabajo como medio de emancipación de los jóvenes shuar, de manera similar a cuanto planteaban para los jóvenes de la periferia de Turín en donde la congregación había surgido. Conforme a esta visión, los shuar eran seres humanos cuya vida corrupta podía ser 'bien' encarrillada a través de una 'sana' educación - obviamente religiosa- y de la implementación de unos hábitos regulares de trabajo y ocio que exigía la organización del tiempo bajo el control de los mismos salesianos. Al fin y al cabo, se trataba de imponer una rígida disciplina basada en tres pilares: el trabajo, la escuela y la catequesis (Botasso 2011).

Cabe matizar que, entre 1880 y 1914, el auge del caucho cambió el panorama económico y social de la Amazonía. Destaca Taylor (1994a) que la entrada a la Amazonía ecuatoriana de los caucheros tenía lugar por el sureste, desde Perú, subiendo el curso de los ríos, y que buscaban tanto el producto como la mano de obra para extraerlo. También los shuar participaron de este comercio, ya fuera a través de un sistema de enganche, $u$ ofreciéndose como fuerza de trabajo gracias a los intermediarios. De todas maneras, parece ser cierto que el grupo, a diferencia de otros cercanos, se salvó de los efectos más devastadores conexos a la explotación de la goma.

Cuando los liberales accedieron al poder en Ecuador, aplicaron medidas para favorecer una mayor integración del país en el mercado mundial, y para modernizarlo. ${ }^{7}$ Entre otras, aprobaron la expulsión de los sacerdotes extranjeros. Precisamente, los salesianos fueron acusados de haber apoyado a los grupos conservadores en la lucha contra Eloy Alfaro. La contienda se terminó en 1902 con un arbitraje

6 Los trabajos del salesiano Juan Botasso $(1993,2011)$ son fundamentales para acercarnos al estudio de la obra salesiana en la Amazonia ecuatoriana en lo que se refiere a los shuar y a la relación entre ambos grupos. Entre las obras más reciente se señala Vázquez et al. (2014). Para un acercamiento al estudio de los shuar, siguen siendo imprescindibles los textos 'clásicos' de Rivet (1907-1908) y de Karsten (1935)

7 Véase al respecto, en particular Clark 2004; Coronel y Prieto 2010; Ministerio Coordinador de Desarrollo Social 2008; Quintero y Silva 2001. 
internacional que dio la razón a los salesianos (Guarnieri Calò Carducci 2001: 197). Nos consta que los salesianos italianos fueron expulsados del país, con excepción de los que se hallaban en el Suroriente, dedicados a actividades misioneras entre los shuar. Efectivamente, las dificultades del Estado para ejercer el control del territorio amazónico llevaron a los gobiernos liberales a tolerar a los salesianos, intentando que favorecieran el proyecto estatal de aculturación de los indios, y la defensa del territorio nacional (frente al supuesto peligro procedente del Perú). Fue precisamente en la primera mitad del siglo XX cuando los salesianos acentuaron, teórica y prácticamente, el contenido 'civilizador' y 'patriótico' de su proyecto (Bottasso 1993: 87).

En este sentido, Muratorio (1992: 19) destaca que el Estado liberal ecuatoriano favoreció la obra misionera, ya que, además, las misiones cumplían un papel fundamental en lo que concierne a la inserción de la mano de obra indígena en la economía nacional ecuatoriana, debiendo ser los shuar, en un futuro cercano, trabajadores sumisos y consumidores de las manufacturas que ellos mismos producirían.

Cabe subrayar que el objetivo de los salesianos era la sedentarización de los shuar, cuyo nomadismo dificultaba la realización del proyecto civilizador. No es casual el apoyo de las élites económicas de Azuay y de los gobiernos ecuatorianos al proyecto misionero. Es sabido que sedentarizar a los indios significaba educarles en el trabajo para transformarles así en ciudadanos productivos y útiles, que contribuyeran, como trabajadores, a la exportación de artículos locales tales como el caucho y la cascarilla (Pagnotta 2017).

El grupo dirigente regional azuayo fue firme partidario de la misión salesiana en el Oriente, para la que demandó, no siempre con éxito, la protección del poder central. Hay que tener en cuenta que ya antes, en 1898, había surgido en Cuenca la Sociedad Protectora de las Misiones Salesianas de Méndez y Gualaquiza (Brito 1935: 381), con el fin de favorecer la transformación de indios en trabajadores 'útiles'.

La fase culminante de este proceso se produjo en la década de 1920, cuando en Ecuador se creó, por un lado, la Dirección General del Oriente y, por otro, se consolidó a nivel político e ideológico el orientalismo que promovía la plena integración del territorio amazónico al Estado ecuatoriano, gracias, en primer lugar, a la implementación del conocimiento geográfico y etnológico de la Amazonía, y, en segundo, a la construcción de vías de comunicación y a la colonización de la región por parte de inmigrantes (Esvertit Cobes 2014: 495-509).

Por lo que concierne más en concreto a la población shuar, afirma Bottasso (2011: 26) que la mentalidad de la época veía a los indios como 'salvajes' porque se habían visto dañados por el aislamiento, por el ambiente en el que vivían, y por el hecho de no conocer la 'verdadera' religión. El deber de los misioneros era, en consecuencia, separar a los niños de aquel ambiente malsano en el que estaban destinados a corromperse, aislarlos de sus familias, y someterlos a una disciplina basada en la observancia de un horario establecido y de un ritmo de vida organizado alrededor del trabajo, la escuela y la catequesis. Afirma el padre Calcagno (1894: 285-286):

En nuestra educación ciframos todas nuestras esperanzas, principalmente en lo que toca a los jíbaros, infundiendo en el corazón del pequeño salvaje, poco a poco, sin violencia, los principios de nuestra Santa
Religión; haciéndoles tocar con la mano las inmensas ventajas que la vida cristiana y civilizada tiene sobre la de sus padres: educándoles desde sus tiernos años en el trabajo y en la moralidad se formará una nueva generación de hombres verdaderamente cristianos, trabajadores y útiles.

Consecuencia de ese planteamiento fue la puesta en marcha del sistema de los internados para los pequeños shuar. El primero surgió en Méndez en el año 1927. En los internados se preveía la formación de los niños con el fin de que crearan, una vez adultos, una familia 'cristiana' a la que se pensaba dejar al cuidado de una pequeña porción de tierra - bajo tutela de la misión-, para el autoconsumo (Esvertit Cobes 2014: 498). ${ }^{8}$

\section{LAS EXPLORACIONES DEL TERRITORIO Y LA RECOGIDA DE LOS} OBJETOS

En 1923, el salesiano Carlo Crespi -licenciado en Ciencias naturales por la Universidad de Padua- se trasladó a Ecuador para encargarse de la nueva 'oficina de propaganda' de la misión de la congregación en el país andino. Entre sus tareas tenía la de documentar 'científicamente' los avances de la misión entre los shuar, con vistas a su presentación en la Exposición Misional Vaticana de 1924-1926, y en la Exposición Salesiana de 1926, y la de diseñar un estudio científico del territorio, también desde la perspectiva técnica y agrícola, para elaborar un plan de colonización que se llevaría a cabo con elementos italianos.

Ya en 1923, envió a la casa madre salesiana los relatos del viaje desde Génova hacia la Amazonía ecuatoriana y sobre las exploraciones que siguieron. Algunos fueron publicados en diferentes números del Bollettino Salesiano de aquella época. En los relatos emergía su formación de científico y destacaban las descripciones de la flora, de la fauna y de la historia de los lugares que encontraba en su recorrido (Crespi 1924a: 68). Un apartado especial merece la descripción etnográfica y de usos y costumbres de los indígenas de la sierra alrededor de Quito. Es interesante el modo en que él enfatizaba que la religión católica debía ser verdaderamente interiorizada entre los quichua. Aquí encontramos un tema recurrente en sus escritos, y que refleja el peso de la mentalidad de la época en América Latina: ya desde su llegada empieza a aplicar la distinción entre los quichua de las tierras altas - ya civilizados-, y los shuar, de tierras bajas, todavía salvajes pero susceptibles de ser civilizados, destacando además lo poco que quedaba entre los primeros de "paganismo», y aplicando desde un comienzo la identificación tan en boga en la época entre paganos e indios salvajes (Crespi 1924b: 71)

Una vez llegado a Cuenca, organizó las primeras excursiones por las zonas de Méndez, Gualaquiza e Indanza, ${ }^{9}$ para recopilar objetos para las dos exposiciones, y también -conforme a la misión que se le había encargado- para ampliar el conocimiento sobre la geografía del vicariato, sus recursos

8 Según Bottasso (1982: 45-46) una de las críticas más fuertes de los salesianos respecto a los shuar era la poligamia masculina y los matrimonios pactados.

9 En 1894, los salesianos se instalaron de forma estable en Gualaquiza; la misión de Indanza fue fundada en 1914, y la de Méndez, en 1916. 
y sus habitantes, y así trazar planos prácticos para la evangelización y la civilización. El eje tenía que ser una escuela agrícola experimental de productos tropicales con vistas a su comercialización y a convertirse en un «polo atractivo de las energías salvajes». ${ }^{10}$ Como se dice en el Bollettino:

Es difícil convencerles [a los salvajes] de vivir con el misionero. El encanto de la floresta afecta demasiado a sus almas, anhelantes de libertad [...]. La reorganización de la Misión necesita entonces grandes medios. Los cultivos de cáñamos tienen que ser extensos, para que sean abundantes los frutos para mantener a los salvajes de paso; las comunicaciones con las jibarías tienen que ser más rápidas con caminos viables y puentes seguros; los locales de las Misiones tienen que ser renovados según las nuevas exigencias (Crespi 1924c: 125).

Los talentos y las labores de Crespi se dirigían en múltiples direcciones, ya que sus exploraciones iban a la par con lo que él definía como su trabajo de «estadística» sobre las poblaciones que componían el vicariato. Mientras recogía «bellísimos pájaros» para la Exposición Vaticana, actuaba para la evangelización de la población shuar logrando, por ejemplo, la promesa del jefe Sandu de una jibaría en la zona del río Santiago, de que todos sus hijos serían enviados a la misión para su educación (católica, sin lugar a dudas) (Crespi 1924d: 266-269).

En las descripciones de viaje del misionero destacaban las dificultades encontradas, que eran varias entre el mal estado de los caminos y la falta de verdaderas carreteras que permitieran un viaje rápido, ágil y seguro. También los precipicios, la falta de puentes para cruzar los ríos, las condiciones climáticas desfavorables, las enfermedades, los ataques de animales feroces, las dificultades encontradas en la obra evangélica, la tozudez y la resistencia de los shuar hacia el reconocimiento y la aceptación del verdadero Dios, y la dificultad en recopilar el material pedido desde Italia, entre otros, eran elementos que obstaculizaban sus proyectos. En medio de todo eso emergía la figura de Crespi, y más en general la de los misioneros que, a pesar de todo, en medio de dificultades inenarrables, de tipo ambiental y personal, lograban los objetivos establecidos gracias a la ayuda divina.

Además, aparecían con claridad las habilidades de Crespi como narrador: sus relatos de viaje eran similares a los de un cuento de aventuras, y tenía gran capacidad para utilizar el suspense, para crear expectación en el lector y afición por sus relatos (cuyo protagonista y héroe es indudablemente él mismo). Por ende, sus narraciones estaban repletas de anécdotas sobre los riesgos vividos, las astucias demostradas, todo lo logrado y llevado a buen fin. Hay que subrayar que, en su papel de científico, recopiló musgos, líquenes, coleópteros, pájaros (que luego disecó), y helechos, entre otras plantas y animales destinados a ser enviados a la península italiana.

De vuelta de la exploración a la zona del río Santiago, Crespi llevó a cabo un primer envío de objetos para la Exposición Vaticana, y, al cabo de poco, se dirigía hacia la sede misionera en Indanza. El viaje, según el narrador

10 Archivio Salesiano Centrale (en adelante ASC). Caja A875. Corrispondenza con Santa Sede - Relazioni a Santa Sede. Vicariato apostólico de Méndez y Gualaquiza. Comin, Domenico, Cuenca, 14 de noviembre de 1924.
(Crespi 1925a: 68), fue el más desastroso de todos debido a las enormes dificultades de la empresa proyectada en uno de los lugares menos favorables y más peligrosos de los territorios de la misión de Indanza - según lo narrado por el mismo Crespi-. Entre las dificultades se enumeran una serie de accidentes ocurridos en el trayecto de ida.

En todo caso, el ojo científico entrevió la maravilla de la naturaleza presente y las posibilidades de desarrollo futuro ${ }^{11}$ en el caso de que un gran plan de ocupación del territorio y de puesta en marcha de la producción de los productos locales viera finalmente la luz:

El viaje nos ofreció panoramas estupendos, nos mostró maravillosas posiciones desiertas que podrían ser la sede feliz de millares de familias de emigrantes. El mes mariano de mayo nos ofreció además [durante este viaje] sabrosísimos frutos silvestres que formarían, si cultivados, la delicia de tantos mercados europeos o americanos (Crespi 1925b: 158).

Destacamos que, en sus exploraciones, Crespi siempre iba acompañado de su cámara fotográfica, y, como atestiguan sus relatos publicados, fotografiaba 'salvajes' en los ambientes naturales de los lugares encontrados. Parte de estas fotografías formaban parte del conjunto de objetos exhibidos en las exposiciones, pero no sabemos mucho más de su ubicación actual. Intuimos que algunas de ellas eran las que fueron publicadas en los periódicos de la época cuando hacía referencia a la exposición de Guayaquil, por ejemplo, o las que acompañaban los relatos de Crespi publicados en el Bollettino.

El primer semestre de 1925 transcurre para Crespi entre el estudio del idioma shuar y la recolección del material para enviar a la Exposición de Turín. Luego, cuando ya había sido enviada parte de los materiales, llegó la orden de la casa central salesiana de enviar animales vivos. El sacerdote, obedeciendo al pedido, organizó lo necesario para recopilar pájaros y animales raros. El 24 de marzo, según lo declarado por Crespi, ya se estaban enviando jaulas con animales vivos y "objetos etnográficos» (no identificados). ${ }^{12}$ Hay que destacar que este envío de material vivo no hubiera sido posible sin la fundamental ayuda de los grupos que vivían en los territorios explorados por el salesiano. En particular, en varias ocasiones, fueron los jóvenes shuar - nombrados oscuros héroes de la exposición- quienes fueron a capturar los pájaros con sus cerbatanas ("La solenne chiusura dell’Esposizione Missionaria salesiana» 1926: 290).

Finalizo este apartado recordando que la idea de que esta fue la misión más peligrosa de todas aparece a menudo en los escritos de Crespi. Esta idea contribuye a recrear la imagen del misionero como héroe. La misma idea se desprende de la correspondencia enviada por él desde Ecuador, y también por otros misioneros en el mismo período. No es casual que, a menudo, fueran publicados en el Bollettino,

11 «Oh! ¡Si fuera a ver al Padre Amado, las magníficas cataratas, la abundancia de agua y la espontaneidad de los diseños y las alturas fabulosas! ¡Cuántos millones de caballos de fuerza eléctricos podrían desarrollarse! iY piense que estamos a sólo 20 millas del Pacífico!» (Crespi 1925a: 68).

12 ASC. Caja Carlo Crespi. Apostolic Vicariate of Méndez and Gualaquiza. 275 - Crespi Carlo - 1935 XII 31. Crespi, Carlo. Breve Relazione sui fondi raccolti da Padre Carlo Crespi dal novembre 1922 al novembre 1935, manuscrito. 
entre las noticias que hablaban de Ecuador, los pedidos de ayuda económica, para sustentar la misión, bajo autoría del vicario monseñor Comin. Parece, más bien, que conectar entre ellos estos elementos sirve para desvelar los logros que los misioneros estaban tratando de alcanzar en la Amazonía ecuatoriana, así como el apoyo internacional que se estaba pidiendo para la consecución definitiva de esos mismos logros superando las adversidades.

La participación del Estado ecuatoriano en las exposiciones universales, desde finales del siglo XIX, proporcionó a las elites del país andino un escenario para representar idealmente en el exterior su comunidad, y un pasado indígena que sirviera a las mismas elites que así la representaban (Muratorio 1994b: 162). A nuestro parecer, aquí encontramos una dinámica similar a la desplegada en el contexto católico.

\section{MiREMOS HACIA EL ORIENTE O LA EXPOSICIÓN ETNOGRÁFICA DEL ORIENTE}

Los primeros días de agosto del año 1924, el buque Nave Italia, en su gira internacional - cuyos objetivos eran promover las relaciones comerciales, buscar nuevos socios económicos en América Latina, y fortalecer los vínculos con los grupos italianos en el continente-, ancló temporalmente en Ecuador (Pagnotta 2016, 2017, 2018, e. p.). Cabe subrayar que la gira formaba parte de un renovado interés italiano y expansionista hacia América que se estaba desarrollando en los círculos conservadores desde finales del siglo XIX. En su fase inicial, el fascismo recuperó estas ideas de colonización pacífica ${ }^{13}$ de los territorios latinoamericanos, y el proyecto era llevar a cabo esa colonización mediante el comercio, la cultura y la emigración.

En homenaje a esa llegada a Ecuador se celebraron varias actividades, entre ellas la inauguración de la Exposición Etnográfica del Oriente que había organizado el Padre Crespi. Miremos hacia el Oriente. La exposición del Padre Crespi es el titular que aparece en el periódico El Universo, de Guayaquil, el día 29 de agosto de 1924. En aquellos días tenía lugar la exposición, y el periódico rendía homenaje a la misma y a su comisario publicando un artículo de apoyo al trabajo de la misión salesiana en la Amazonía y a los planes de desarrollo dibujados por Crespi. Cabe destacar nuevamente que la Amazonía ecuatoriana de aquel entonces era un territorio en gran parte desconocido para la mayoría de los ecuatorianos de la época. El periódico, pues, parecía decir que hacía falta mirar hacia el Oriente y ver lo que había, invitando a recoger el espíritu de la exposición.

Un contingente bastante grande del material que iba a ser enviado hacia Turín, para ser exhibido en la Exposición Misional Vaticana y en la Exposición Misional Salesiana, fue expuesto en una "simpática exposición orientalista» en la plaza de la catedral de Guayaquil, en la planta baja de la casa del poeta Víctor Rendón. La exposición duró 40 días y acogió alrededor de 120 conferencias, con la participación de los alumnos de las escuelas públicas y privadas de primaria y de secundaria. En total, los visitantes fueron $30.000 .{ }^{14}$ Sabemos que en esa ocasión Crespi dio una conferencia sobre la Amazonía, con la presencia de la tripulación italiana, en la que se destacó que en el Oriente había animales y plantas desconocidas (algunos líquenes, en particular) que él presentó al auditorio. Trató por último de los shuar, reseñando "la obra cristiana y civilizadora», y refiriendo además que Mussolini había hecho obsequio de la misión y de su importante obra «en el bien de la humanidad y de la civilización» ( «La real nave Italia en Guayaquil» 1924).

Otro periódico de la ciudad ecuatoriana, El Télegrafo, al describir dicha exposición, enfatizaba la implicación de las autoridades civiles y religiosas en el proyecto civilizador acerca de los shuar. Matizaba, además, de qué manera la exposición se dirigía primero a los navegantes, tratando de mostrarles con fotografías la belleza del Oriente, a fin de que pudieran «abrir los ojos a los ecuatorianos» hacia ese territorio desconocido («Exposición etnográfica sobre los jíbaros» 1924). Este periódico avanza, además, su explicación de las finalidades de la exposición en Guayaquil, ya que esta "servirá para demostrar en pequeño, la gran riqueza del Oriente ecuatoriano, y los esfuerzos hechos por las autoridades civiles y religiosas, a fin de hacer entrar en el juego de las fuerzas civilizadoras a los simpáticos jíbaros de las florestas» («Exposición etnográfica sobre los jíbaros del Oriente ecuatoriano» 1924).

Los jíbaros presentados por el periódico devienen aquí 'simpáticos', con la intención evidente de captar el cariño y los intereses del público de lectores y visitantes de la exposición hacia el Oriente y sus 'simpáticos' habitantes. No encuentra aquí cabida la presentación o representación del salvajismo de los pueblos misionados, que a veces aparecía en los escritos de Crespi publicados en el Bollettino. A diferencia de otras imágenes contemporáneas, no se trataba aquí de representar al buen salvaje, lo exótico en su ambiente natural; más bien se trataba de presentar el territorio misionado como zona potencialmente explotable por los capitalistas nacionales e internacionales. ${ }^{15}$ La secuencialidad del discurso civilizatorio deviene aquí evidente, mostrando a los salesianos como los primeros que han abierto estas tierras al camino hacia la civilización, y requiriendo, para poder cumplir el paso consecutivo, el apoyo y el interés económico, cultural y material de capitales privados. Solo con el aporte de ambos actores la zona oriental del Ecuador podría alcanzar la civilización y, con ella, la entrada en la economía mundial.

Las palabras publicadas en los periódicos guayaquileños, que sirven para presentar la exhibición, son, sin lugar a dudas, explícitas. Las florestas orientales son presentadas como «las más hermosas del mundo y las más ricas en esencias medicinales y tintóreas; allí están las reservas más importantes de las colosales industrias futuras: allí, dentro de pocos años, se formarán las mayores ciudades del mundo y serán notables centros de civilización» («Exposición etnográfica sobre los jíbaros del Oriente ecuatoriano» 1924). También el proyecto donbosquino es resumido y presentado en su contenido civilizatorio por el periódico ecuatoriano,

13 Se imaginaba como pacífica debido a la falta de medios económicos y militares que padecía la Italia de la época.

14 ASC. Caja Carlo Crespi. Apostolic Vicariate of Méndez and Gualaquiza. 275 - Crespi Carlo - 1935 XII 31.

15 Recordamos como Crespi trabajo intensamente con los círculos políticos y económicos ecuatorianos. Para más detalle al respeto véase Pagnotta 2017. 
poniendo énfasis en la educación en el trabajo desarrollada por la congregación. ${ }^{16}$

Nos consta que, en la entrada de la exposición, se encontraban la reconstrucción de una casa shuar, y dos mapas geográficos, uno de Turín, y otro en el que se da a conocer el resultado de las exploraciones llevadas a cabo por los salesianos en las zonas de Santiago, Zamora, Morona y Upano. Se exhibían luego varios tipos de armas de caza utilizadas por los shuar, un amplio espectro de cerbatanas y flechas utilizadas para matar a los pájaros de la selva, y varias lanzas de chonta fabricadas todas por los shuar. Se destacan las habilidades manuales del grupo ${ }^{17}$, exponiendo también algodón, hilo, tejidos, máquinas para hilar (definidas como primitivas), y dos telares completos, así como cortezas de árbol tan flexibles que eran utilizadas para vestirse. También se reconstruían dos habitaciones, una para varones y una para mujeres. Destacaba además una colección de pájaros cazados y disecados por los mismos shuar. La sección de adornos estaba compuesta sobre todo por elaboradísimos ornamentos hechos con plumas de pájaros y semillas varias, para hombres y para mujeres, coronas brillantes, collares, sombreros hechos a partir de las labores del cuero de los monos, etc. En ese momento se exponían casi 300 placas fotográficas de fotografías hechas por Don Crespi y Don Ghersi. El artículo de El Télegrafo terminaba con una exhortación a visitar la exposición:

Vayan los niños para enriquecer su mente con tantas nociones geográficas y etnográficas interesantes. Vayan los padres de familia, a fin de tener una idea, aunque imperfecta, de nuestro Oriente. Vayan sobre todo los ardientes patriotas, los capitalistas, a fin de estudiar la manera de empezar una labor activa, eficaz, en favor de la conquista de tierras tan fértiles y tan preciosas («Exposición etnográfica sobre los jíbaros» 1924).

En estas pocas líneas emerge con fuerza uno de los objetivos de esta exposición: para proyectar una presencia más consistente y funcional del poder civil y militar en la Amazonia, primero hay que conocerla y percatarse de los recursos humanos y materiales que allí se encuentran, y es necesario conocer a quienes actúan en aquel territorio, principalmente los salesianos, llevando a cabo el proyecto civilizatorio de aquel territorio. Los dos periódicos de Guayaquil, ambos de orientación liberal, eran entusiastas de la exposición -en particular El Telégrafo-, y escenificaban perfectamente la coyuntura y la comunión de intereses

16 «Un ilustre sacerdote, Don Bosco, iniciador de las escuelas de artes y oficios en Italia, en un sueño, tenido el año 1883, describía, con los colores más vivos, las florestas de nuestro Oriente y el desarrollo de potentes ferrocarriles en una región que parecía fabulosa. El sueño del gran vidente se va cumpliendo a maravilla: ya las más poderosas sociedades del comercio y de la industria, con verdadero afán, exploran el Oriente, a fin de poder sacar fácilmente las poderosas materias primas, para sus grandes industrias. Para los ecuatorianos es de máxima importancia el conocer su tierra, conocer su Oriente, apreciarlo y, sobre todo, hacer efectivo su dominio, con numerosas colonias en la prodigiosa zona con que les ha brindado la naturaleza» («Exposición etnográfica sobre los jíbaros del Oriente ecuatoriano» 1924).

17 «El jibaro muestra un gusto exquisito y una grande fineza en sus ornamentos [...] Allí se ve como del cuero del mono, el jibaro sabe sacar coronas y sombreros lindos: de las plumas de las mejores aves, adornos para las orejas, la cabeza, el pecho» («Exposición etnográfica sobre los jíbaros del Oriente ecuatoriano» 1924). sobre el Oriente que unía, a pesar de todo, a los liberales (a nivel nacional y a nivel local) y a los misioneros salesianos. ${ }^{18}$

El 4 de septiembre, el periódico El Universo dedicaba algunas páginas al tema surgido de la exposición, los «Mirajes al Oriente Ecuatoriano. Lo que vale esa gran porción de territorio patrio», acompañando la descripción con algunas fotografías. Algunas de ellas aparecerán en otras publicaciones ecuatorianas de la época ${ }^{19}$, dejándonos así suponer que estas imágenes eran una representación recurrente del Oriente ecuatoriano, sus habitantes y sus recursos.

FiguRAS 1, 2 Y 3

Mirajes al Oriente Ecuatoriano. Lo que vale esa gran porción de territorio patrio

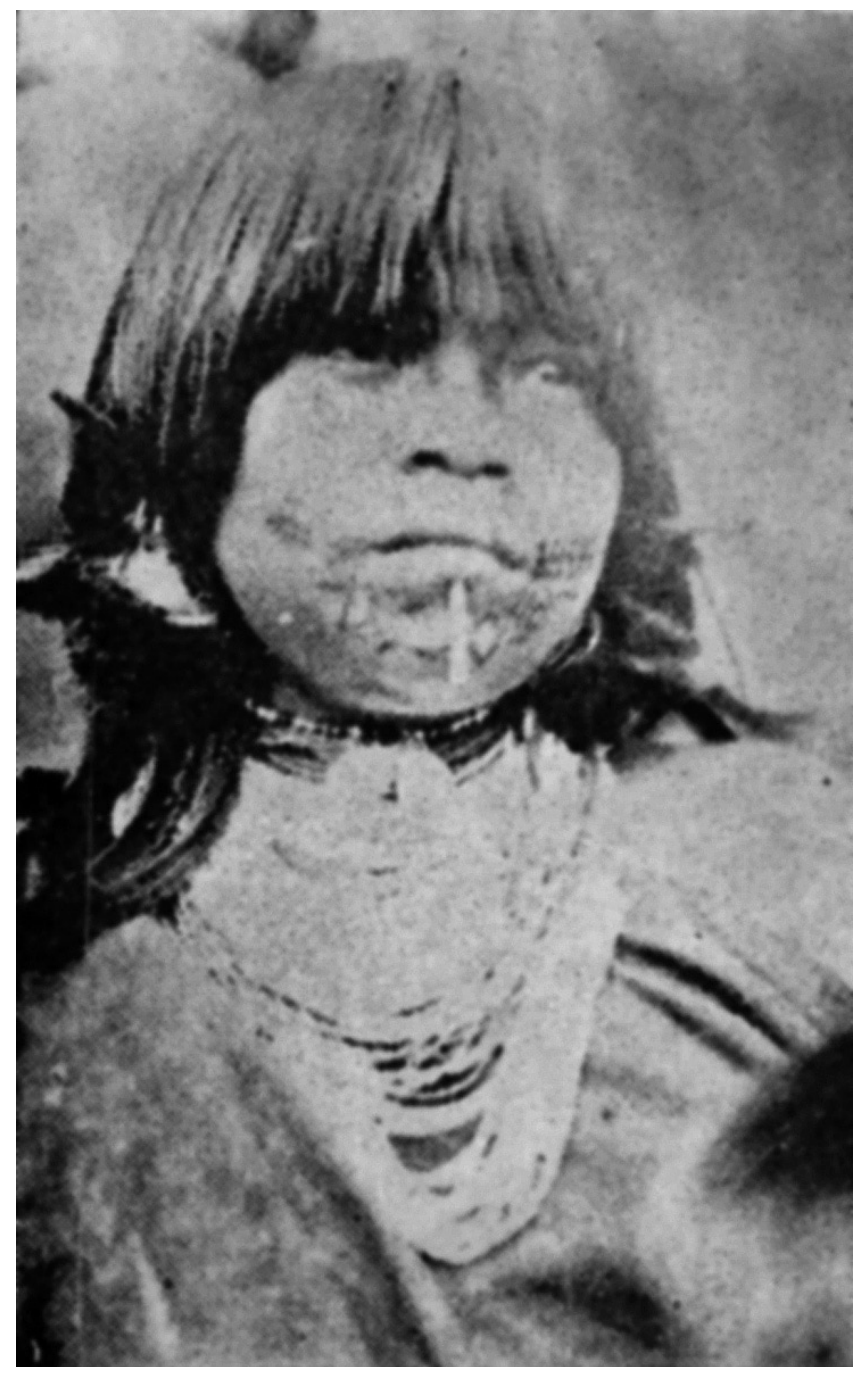

18 «Guayaquil, la Perla del Pacifico, la ciudad patriótica por excelencia, de su ejemplo práctico y eficaz, levantando en el lejano Oriente un puente sólido y grandioso que suprima un abismo y permita a nuestros militares, a nuestras autoridades, bajar pronto a los sagrados límites de la Patria todavía ocupados por tigres, serpientes y salvajes pasivos [...] Los abnegados misioneros salesianos, patriotas ardientes, que en estos años con heroico trabajo y con perseverante entusiasmo han podido llevar a cabo no solo estudios importantes, sino abrir caminos, levantar puentes, preparar material para el desarrollo de intensas colonias son las [no se entiende] nuestra confianza y estamos seguros que el céntimo depositado en sus manos será sagrado y se convertirá en una obra provechosa para la Nación» («Exposición etnográfica de los jíbaros del oriente» 1924).

19 Véase Pagnotta 2017. 

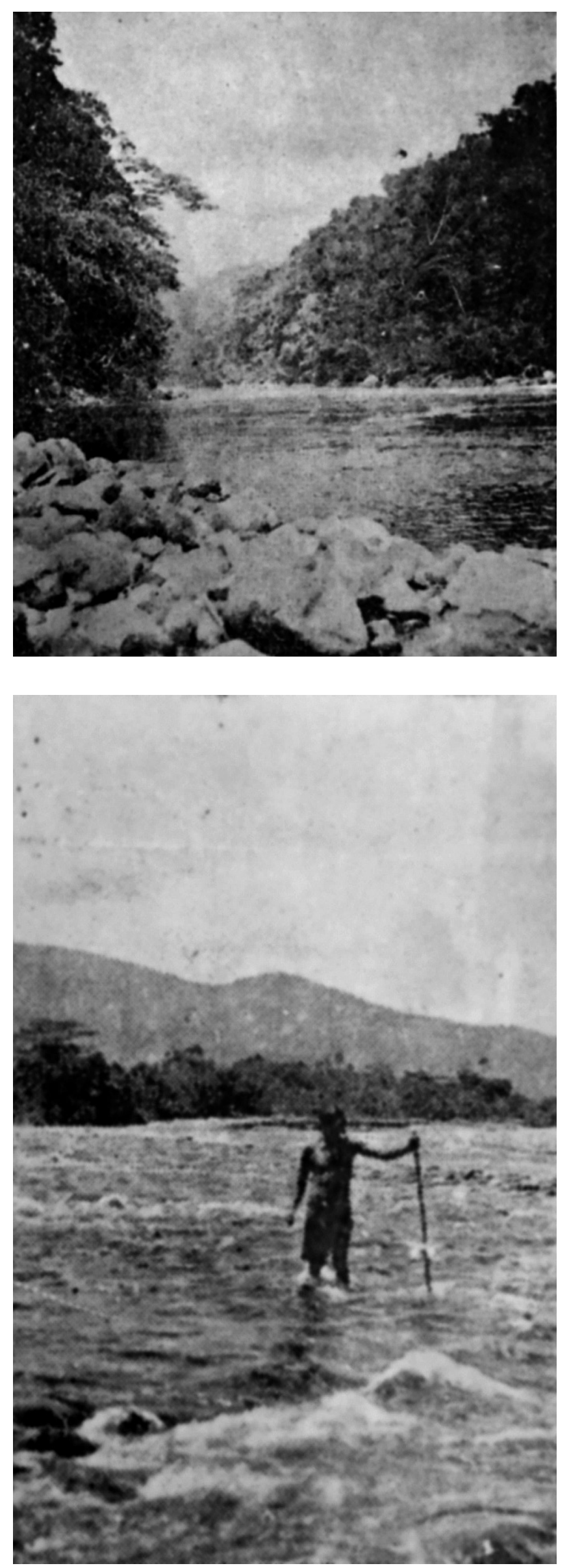

Fuente: El Universo, 4 de septiembre de 1924.
Entre las siete fotos, hemos escogidos las que se muestran en las Figuras 1, 2 y 3, ya que, a nuestro parecer, simbolizan bien el contenido del artículo y, más en general, de la exposición.

Cabe destacar cómo seres humanos y naturaleza son representados aquí en función del mensaje que se quería presentar, es decir, como una tierra con inmensos recursos explotables y una población hábil para explotarlos. En este sentido, la primera foto, de una mujer shuar (el pie de foto sitúa: «Jibara de Méndez, en traje de gala») es útil para presentar las habilidades manuales de las mujeres en la producción de los adornos y tejidos que utilizan (sean aretes, collares, pinturas o vestimentas). La segunda imagen, del río Zamora (cuyo pie de foto reporta: «El rio Zamora en el Oriente ecuatoriano. Prodigiosa vegetación que se eleva en una y otra orilla»), y la importancia dada a la vegetación, parece sugerir la posible explotación futura de la madera de la zona. Mientras la tercera («El capitán Tomassa entre las ondas del poético rio Bomboiza (Oriente ecuatoriano)») podría sugerir la utilización de las fuerzas hidrográficas del río Bomboiza.

Cabe matizar cómo, por parte de los periódicos del puerto, los aspectos menos 'civiles' de los proyectos salesianos fueron escasamente mencionados, sobre todo aquellos que se fijaban en la evangelización de los shuar. De otro lado, es cierto que, como hemos dicho ya, en esta coyuntura histórica y de cohabitación obligada con un gobierno liberal en Ecuador, teóricamente hostil, los salesianos acentuaron aquellos aspectos del proyecto que más interesaban a la élite en el poder, los de la misión civilizatoria, dejando en un segundo plano los aspectos que podían suponer un contraste entre los misioneros y el gobierno del país de misión.

Conforme a lo señalado en los periódicos, con ocasión de esta exposición, parece empezar a trazarse un plan civilizatorio, que nunca verá la luz, y que pretendía llevarse a cabo, con la inmigración europea, en territorios fronterizos con el Perú en los que vivían los shuar («Miremos hacia el Oriente» 1924). Por un lado, por parte salesiana, se pensaba que la presencia de colonos civilizados podía facilitar y dar rapidez a la civilización de los grupos no reducidos (Mattana 1907) y, además, por parte del Estado ecuatoriano, poblar la frontera con el Perú era fundamental para su defensa.

En todo caso, la conquista del sector liberal de Guayaquil - llevada a cabo con la exposición - fue todo un éxito, como matiza con orgullo personal Don Crespi:

Los grandes dolores brotaron aquí en Guayaquil una flor hermosa de entusiasmo para la misión. Es el trabajo de Dios: la obra de su gracia [...] durante estos dos meses de intensa propaganda he podido conquistar todos los periódicos liberales a favor de las misiones. No sólo idealmente, sino prácticamente. La exposición en el corazón de la ciudad fue una verdadera revelación. Era un espectáculo simplemente científico y etnográfico que entusiasmó todo a el mundo, y en vez de mantenerlo abierto durante tres días, tuvimos que tener abierto durante más o menos un mes hasta las 23 horas de la noche para hacer [incomprensible] para los grandes banqueros y exportadores de cacao y café. ${ }^{20}$

20 Archivo Documental y Fotográfico Salesiano de Quito (en adelante ADFS). Caja P. Crespi Documentos. Crespi, Carlo. Lettera a D. Rinaldi da Guayaquil. 20 de noviembre de 1924. 
La última frase de Crespi nos hace entender, una vez más, que uno de los intereses de los salesianos de la época era sensibilizar a los grandes banqueros y exportadores de cacao y café que tenían sus bases económicas en el puerto ecuatoriano, y cuyas conexiones políticas con el partido del gobierno del país eran muy remarcables. Una vez más, parece que mostrar el Oriente a los ecuatorianos, en realidad, significaba mostrarlo a los capitalistas y a los inversores para que pudieran desarrollar ahí sus actividades económicas y contribuir, consecuentemente, a la sedentarización de los shuar y a su transformación en mano de obra útil para la explotación del territorio amazónico y sus recursos, primer paso para poder proceder a su evangelización por parte de los salesianos.

En ese contexto, y en la clausura de dicha exposición, se fundó el Comité Orientalista de Señoras, integrado por mujeres de la alta sociedad, con monseñor Comin en calidad de Director General, y el padre Carlo Crespi como Director Encargado, y cuyo objetivo era la organización de un conjunto de actos de propaganda para la recaudación de recursos económicos destinados al desarrollo del Oriente ${ }^{21}$ y a la civilización de los shuar (Crespi 1924e).

Conviene terminar este apartado aclarando cómo, en los años veinte del siglo $X X$, las élites gubernamentales ecuatorianas compartían la visión de que la única manera de integrar a los indígenas en el Estado en formación era a través de un recorrido educativo, cuyo fin último era la adopción del modelo civilizatorio en boga. Precisamente en este punto, y conforme a lo representado y expuesto en esta puesta en escena, coinciden los intereses de misioneros, élites gubernamentales (locales y nacionales), y capitalistas ecuatorianos e italianos. Esta exposición pone en evidencia que los misioneros salesianos en Ecuador parecen ser parte de aquella 'vanguardia capitalista' que nos presenta los territorios americanos como espacios «dotados de sentido solo en función de un futuro capitalista y de sus posibilidades de producir un excedente comercializable» (Pratt 2010: 125).

\section{LA EXPOSICIÓN MISIONAL SALESIANA}

La Exposición tuvo lugar entre mayo y octubre de 1926. Con autorización del Papa, la sección de los salesianos, que formaba parte de la Exposición Misional Vaticana de 1925, había sido transportada temporalmente a Turín para la exposición propia de la congregación. Eso significaba alrededor de la quinta parte de toda la exposición turinesa («L'esposizione delle missioni salesiane» 1926), en la que se iban a exponer los trabajos que desde hacía 50 años estaban llevando a cabo los salesianos para «traer salud a los cuerpos, luz a las almas, suavidad a las costumbres, redención a las almas de los desgraciados habitantes de las más lejanas e inhóspitas regiones» ("La solenne chiusura» 1926: 284). ${ }^{22}$

${ }^{21}$ ASC. Caja A875. Comin, Domenico, Cuenca, 14 de noviembre de 1924.

22 Cabe subrayar la compleja relación entre el fascismo italiano y la congregación salesiana en particular acerca de la competencia para la educación de los jóvenes. Es sabido que el joven Mussolini trascurrió dos años en el colegio salesiano en la ciudad de Faenza. Además, es úti recordar que con la promulgación de las leyes fascistísimas (1925-1926), el fascismo se construyó como régimen totalitario, y por ende, tuvo lugar
En ese contexto, Carlo Crespi llegó al puerto de Génova, rumbo a Turín, en abril de 1926, ya que en la Exposición Misional salesiana se requería su presencia, y Crespi organizó el material que había traído de Ecuador.

En el jardín de la exposición se había reconstruido, entre otras, una choza shuar. Se mostraba la vivienda, en cuyo interior se veía una cama hecha de caña de bambú, un asiento, un tunduy (un gran tronco de madera vaciado de su pulpa y así convertido en una caja de resonancia que, cuando se golpeaba fuertemente, servía para celebrar fiestas, duelos y guerras), lanzas, coronas de plumas, etc. En el exterior había algunas jaulas de aves vivas, ${ }^{23}$ un tigrillo, y varias fotografías de indígenas shuar y de la selva, y alrededor de 20 pájaros que repetían las palabras shuar imitando las voces humanas («All’Esposizione Missionaria Salesiana» 1926).

Después del jardín, había una primera sala dedicada a Don Bosco, con la maqueta de la visión que tuvo dos años antes de su muerte, en la que se le aparecía la red de misiones salesianas en el mundo. Seguían otras salas dedicadas a expediciones misioneras y, finalmente lo que nos interesa: un pabellón inmenso de las misiones del Mato Grosso, Rio Negro y Ecuador, con ilustraciones de costumbres bororo y shuar. En la entrada estaba la talla de madera de un shuar, de 1,65 de altura, coronado de plumas de aves y con la lanza en la mano. ${ }^{24} \mathrm{El}$ comentarista del Bollettino observa:

El jíbaro es sin lugar a dudas el más salvaje, el más robusto, el más inteligente con el que han tenido que tratar los misioneros [...] y eso lo demuestran los millares de objetos ornamentales que fábrica, en los que destaca un artístico sentido de belleza [...]. Se observan, en un cuadro, una carta manuscrita de un joven jíbaro, después de unos meses de escuela, y una botella en cuyo interior es representada la pasión de Cristo, hecha por un indio ecuatoriano. En otras vitrinas se exponen colecciones de maderas y tejidos, productos naturales y sobre todo una linda colección de sombreros que se comercializan con el nombre de sombreros de Panamá, y que en su mayoría son producidos con palmas de nuestra Misión en Gualaquiza («All’Esposizione Missionaria Salesiana» 1926)

En otro salón se encontraba un dibujo que representaba la obra civilizadora de los misioneros en Patagonia, Mato Grosso y Ecuador. Para el caso ecuatoriano destacaba la imagen de la celebración de la pasión de Cristo en medio de la selva. Nos interesa aquí matizar de qué manera en esta exposición encuentran cabida los logros y los pasos que han dado los shuar bajo la tutela de los misioneros, ya sea tratando de aprender a leer y escribir, a rezar al verdadero

la aniquilación de todo tipo de poderes alternativos. En fin, la relación entre fascismo y congregación salesiana pasó momentos de tensiones alternados con momentos más cordiales (en particular a finales de los años treinta) hasta una definitiva distancia entre los dos con la entrada de Italia en la Segunda Guerra Mundial.

${ }^{23}$ La Stampa del 29 de abril destacaba que «en la exposición de Roma los espectadores han visto solo animales embalsamados, en esta de Valdocco, será posible admirar de cerca, y vivas, unas faunas desconocidas por nosotros» ( «L'esposizione delle missioni salesiane» 1926).

24 Las exposiciones misionales 'vivas' - según la definición de Sánchez Gómez (2006) - son aquellas en las que se exhibían seres humanos como parte del evento. Sabemos que esta tipología de exposición etnográfica misional se dio a finales del siglo XIX en el mundo protestante y en el católico. Aquí, en las primeras décadas del siglo XX, parece prevalecer la utilización de esculturas en lugar de personas vivas. 
Dios, o produciendo objetos de carácter religioso, o sombreros destinados a la venta en los Estados Unidos. ${ }^{25}$

Aparece evidente que esta exposición pretendía mostrar, de un lado, las características de los territorios, y detalles de los grupos misionados, con una descripción etnográfica de las tipologías de viviendas y la exhibición de los objetos de vida material de los shuar, para dar a conocer al público el Oriente ecuatoriano (entendiendo, con eso, el territorio y sus habitantes) en el que estaban desarrollando sus trabajos los salesianos.

De otro lado, la exposición enfatiza la relevancia otorgada a los resultados civilizatorios y evangelizadores del proyecto misionero, mostrando las manufacturas producidas por los shuar, destacando, entre los logros 'civiles', el aprendizaje de la escritura y la producción de objetos (sombreros de Panamá) destinados al mercado mundial, y, entre los religiosos, la creación de una manufactura que representaba la pasión de Cristo. En ambos casos, se trataba de exponer el tránsito desde el salvajismo hacia la civilización gracias a los trabajos de los misioneros.

FIGURA 4

Entre los jíbaros salvajes. Una clase de catequesis

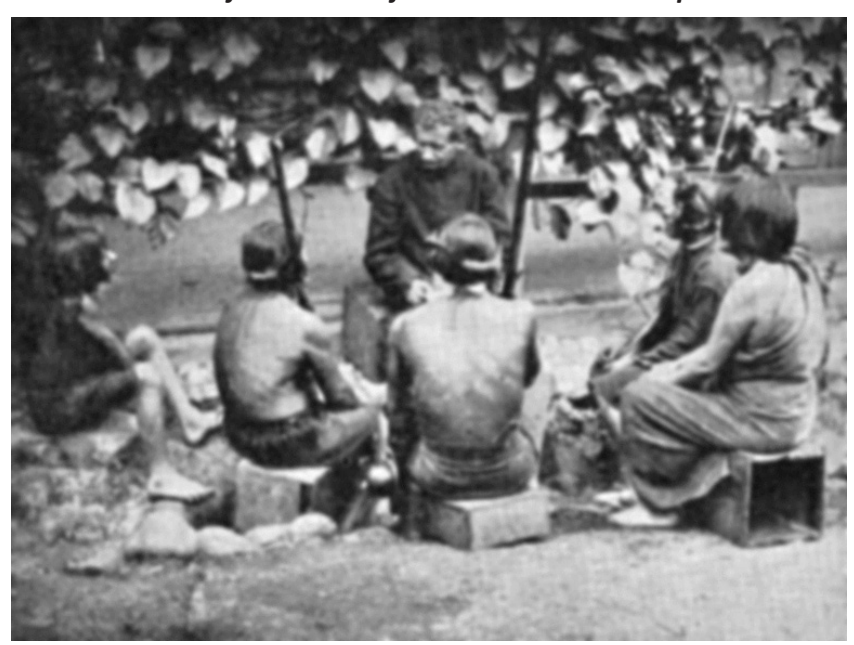

Fuente: Portada del Bollettino Salesiano, Ottobre 1926

En este sentido interpretamos la fotografía (Fig. 4) que abría el número de octubre de 1924, durante la exposición turinesa, del Bollettino ${ }^{26}$. El pie de foto reporta: «Entre los jíbaros salvajes. Una clase de catequesis». La imagen representa varios 'salvajes', de diferentes edades y géneros, mientras están 'tranquilamente' sentados alrededor de un misionero. La atención del grupo y sus miradas están dirigidas hacia el misionero, que está dando una 'clase de catequesis'. La orientación de las cabezas de los jíbaros nos sugiere un aprendizaje atento a las palabras religiosas, para

25 Es sabido que los sombreros Panamá eran producidos en la zona de Cuenca, y que el principal mercado de este producto era Estados Unidos, siendo el centro de distribución Nueva York. Nos parece por ello importante resaltar de qué manera los salesianos, en su obra civilizatoria y evangelizadora, hubieran logrado entrar en ese comercio a escala mundial.

26 Esta, junto con la que presentamos a continuación, son las únicas dos imágenes de los shuar que aparecen publicadas en el Bollettino durante los meses en los que estuvo abierta la exposición salesiana. poner en evidencia, una vez más, cómo el salvajismo ha sido domado con la enseñanza del verdadero Dios.

Por lo que concierne a la disposición de la exposición salesiana, en el Salón de Actos se proyectaba la película Los invencibles shuaras del alto amazonas, que Crespi había realizado en enero de 1926 en el Valle del Upano. ${ }^{27}$ Este es considerado el primer documental etnográfico ecuatoriano en que se describía el viaje de dos exploradores que partían desde Génova e iban a conocer las costumbres y la vida de los shuar, y las actividades que los salesianos estaban desarrollando en la zona. Reportaba el periódico italiano Momento, tratando de captar la atención del lector, y por ende enfatizando el salvajismo y exotismo del grupo indígena retratado en el documental, que:

Las escenas reproducidas ilustran la vida y las costumbres de esos indómitos salvajes, y, entre otras, suscitan un vivo interés la fabricación de la famosa bebida "la Chicha», las preparaciones de festines, orgías, trofeos de guerra. Se admiran espectaculares panoramas, fiestas populares sorprendentes, y gestas increíbles de una civilización bárbara («Esposizione Missionaria Salesiana» 1926). ${ }^{28}$

En estas líneas, escritas por una prensa laica, no relacionada con la congregación salesiana, emerge la visión exótica de la exposición, y su recepción por parte del público de visitantes y periodistas. Se vuelve a proponer aquí una idea europea del exotismo de los pueblos no-europeos, dirigiendo la mirada al desenfreno sexual, alcohólico y de violencia de los shuar. Hay que destacar que esta exposición parecía buscar una cierta teatralidad, mediante el exotismo, y el éxito publicitario al captar la atención del visitante y suscitar simpatía, admiración y apoyo, tratando de que esos sentimientos se difundieran de manera amplia entre todo el público.

En particular, La Stampa del 1 de mayo de 1926 destacaba el valor etnográfico, exótico y generalista de la exhibición:

Esta exposición está hecha para todos. Los devotos encontrarán motivos de satisfacción por el triunfo de la fe que llevaron los misionarios para redimir a las más salvajes tribus; los estudiosos encontrarán un campo de observación en todas las ramas de la ciencia; los profanos, que están motivados por la curiosidad, podrán, sin esfuerzos y sin gastos, dar la vuelta al mundo; los apasionados de las aventuras encontrarán en estas salas abundante material para sus observaciones, y hasta a las señoras no les faltarán motivos de interés personal. No es dado saber si la moda, que ha explotado cada campo para encontrar algo nuevo y original, no encuentre en esta exposición motivos de renovación ( «Le curiosità dell’Esposizione delle Missioni Salesiane» 1926).

Otro tema que aparece, y que es evidentemente uno de los dos que trata de matizar la exposición, es la figura del misionero como héroe, y la narración de los heroicos sacrificios hechos para llegar a exponer los objetos expuestos.

\footnotetext{
27 Este documental ha sido analizado por la autora en Pagnotta 2017.

28 Nos resulta de particular interés la unión de dos palabras tales como civilización y barbarie, siendo, teóricamente, en sus significados, incompatibles.
} 
Describiendo la exposición, los diferentes periodistas resaltaban los riesgos que corrían los misioneros, hablando además del clima insoportable en aquellas regiones y en otras en las que viven igualmente jíbaros y bororo, enumerando las varias enfermedades tropicales, la malaria perenne, las pérdidas que han tenido y la vida de sacrificio continuo y de sufrimiento sin nombre soportados por aquellos pioneros. Se enfatiza el sacrificio de vivir entre los salvajes con el fin evidente de conseguir apoyo ideológico y económico.

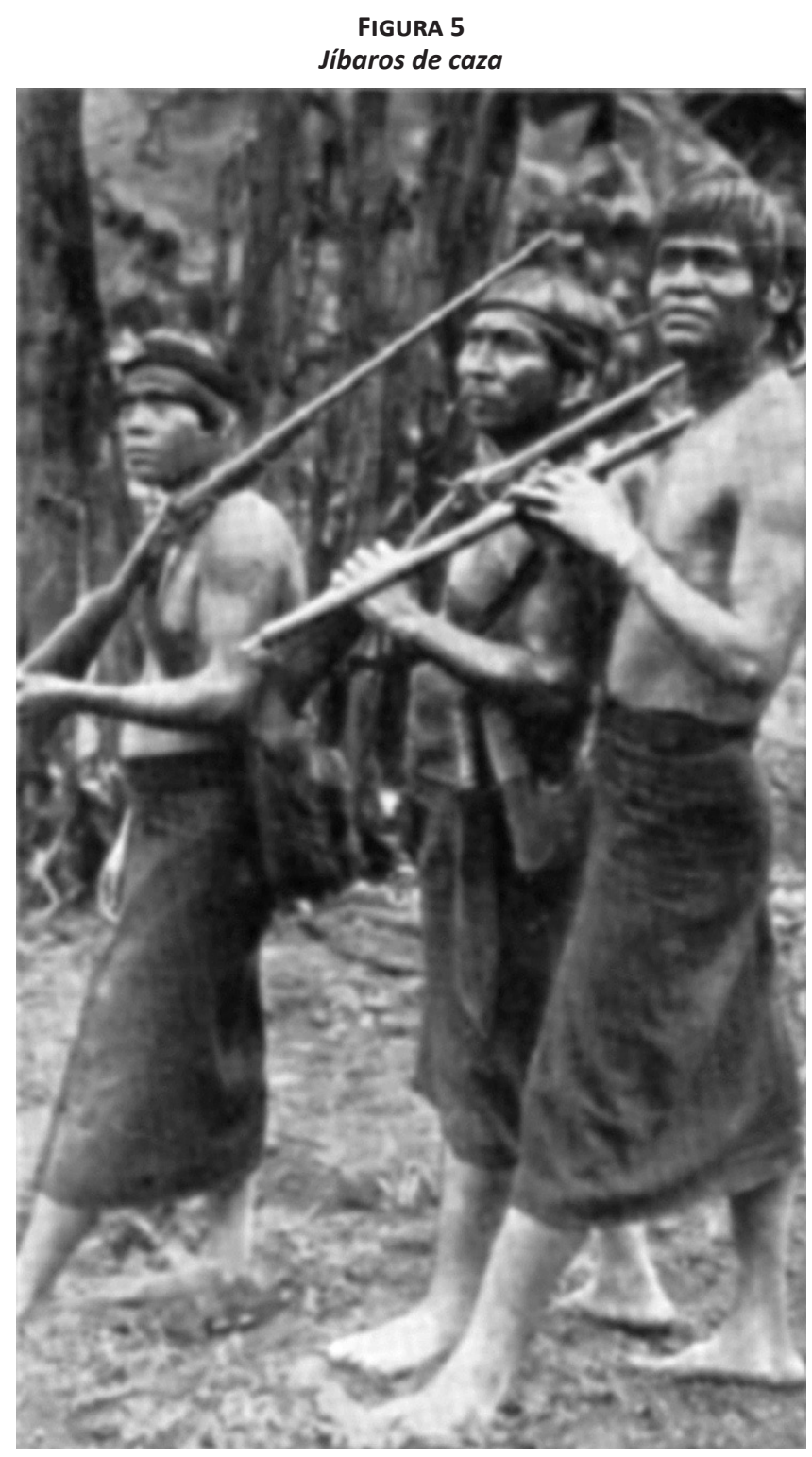

Fuente: Bollettino Salesiano, Ottobre 1926: 265

En este sentido, también la representación del jíbaro como grupo indócil parece orientada a resaltar el heroico trabajo de los misioneros (Figura 5). El pie de foto reporta: 'jíbaros de caza'; aunque la fotografía es evidentemente una puesta en escena en la que tres hombres shuar son presentados juntos con las armas (fusiles y cerbatanas) que utilizan para cazar en la selva.

A nuestro parecer, es particularmente significativo que esta, y la Figura 4 de los shuar en una clase de catequesis, sean las únicas dos imágenes que fueron presentadas a los lectores del Bollettino durante el periodo de la exposición salesiana. Las imágenes remarcan las actividades de conversión y civilización por parte de los salesianos, y el manejo de las armas por parte del grupo que, aunque en una actividad como la caza, deja entrever el pasado belicoso del grupo con el que tuvieron que lidiar los misioneros.

Por lo que concierne a las imágenes que emergen del Bollettino, interesa de manera particular resaltar que el Discurso de clausura de la Exposición, titulado La Exposición y los Misioneros, fue pronunciado por Carlo Crespi, en nombre de todos los misioneros, y fue luego publicado. Crespi empieza su discurso contando un acontecimiento ocurrido durante el regreso de una de sus exploraciones, del que resalta lo cerca que había estado de perder parte de los objetos expuestos a causa del mal estado de las carreteras en un día de lluvia, y dos episodios con dos ladrones. Todo eso, como él mismo afirma, para "hacer entender el alto valor de los objetos» («La solenne chiusura» 1926: 289). Toda su charla fue un homenaje al sacrificio hecho para llegar a realizar la exposición, narrado a partir de episodios vividos. A veces admitió que los pedidos que provenían desde Italia para la recogida de objetos no tenían en cuenta las dificultades en tierra ecuatoriana; pero, en todo caso, señaló que los misioneros siempre aceptaban las tareas bajo el lema de lo imposible no existe, y multiplicando por ende los esfuerzos:

Observamos las cartas geográficas, los itinerarios de los viajes de esos pioneros de la civilidad que se llaman misioneros salesianos, y en su mudo lenguaje os dirán toda una epopeya de sacrificio, martirio, renuncias, dolores, luchas, derrotas y gloriosas victorias («La solenne chiusura» 1926: 289-290).

Destaca el modo en que Crespi agradece con profunda admiración y gratitud a los "salvajes de las florestas», que expusieron su vida para hacer lo que pedía el misionero, remarcando una profunda conexión con los lugares y las poblaciones encontradas durante las exploraciones hechas para que las exposiciones pudieran concretarse:

Y cada collar, cada lanza, cada pájaro, cada objeto canta para nosotros [...] la epopeya heróica de sacrificios de centenares, de millares de salvajes, canta el amor de centenares de misioneros y de hermanas [monjas] inmoladas en un duro trabajo de elevación, sacrificio y dolor ("La solenne chiusura» 1926: 291).

\section{CONSIDERACIONES FINALES}

En este texto he intentado hacer una aproximación al proyecto misionero salesiano, en el Ecuador, de las primeras décadas del siglo $\mathrm{XX}$, tal como vino evidenciándose través de las dos exposiciones en Guayaquil y en Turín, en las que la congregación salesiana - y el Padre Carlo Crespi en particular - tuvo un papel importante tanto en la recolecta como en la organización de los objetos con vistas a su exhibición.

Cabe subrayar que el material exhibido en las dos exposiciones concierne a la Amazonía ecuatoriana y sus habitantes a partir de una mirada occidental y etnocéntrica. Estas representaciones ponen de manifiesto una relación asimétrica entre quienes representan y quienes son representados, sin que estos últimos, en este caso los shuar, tengan voz o medios de expresión para representarse a sí mismos. En todo caso, sin lugar a duda, las exposiciones nos hablan de 
las sociedades y mentalidades de los grupos que representan a 'el otro' en dichas ocasiones.

Se puede sin duda decir que ambas exposiciones fueron un espacio de representación que permitió a la congregación salesiana destacar su voz, su proyecto, y clamar por un mayor apoyo respecto a las necesidades económicas en el contexto nacional (Guayaquil) e internacional (Turín).

En el diálogo con la élite comercial, empresarial, exportadora y, por ende, política, de Ecuador, se difundió la idea de que la misión y la estrategia civilizatoria desarrollada por los salesianos podía transformar a los 'salvajes' shuar y los territorios por ellos poblados en puntas avanzadas de la producción económica y de la nacionalidad ecuatoriana en la frontera con Perú. Creo haber demostrado que no era casual el hecho de que la primera exhibición de objetos provenientes del Suroriente tuviera lugar en Guayaquil, mostrándose primero a los liberales y capas acomodadas del país que tenían su base económica en el puerto ecuatoriano, con la finalidad de que ellos empezaran a conocer y se involucraran en las posibilidades de expansión económica de la Amazonía. Sin lugar a duda, el fin de los salesianos era el de garantizarse el apoyo de los empresarios primero, en relación con la civilización de dicha zona, haciéndola devenir objeto de sus intereses económicos, y luego respecto a su evangelización por medio de la educación (salesiana), centrada en un trabajo 'productivo'.

$Y$ si bien hemos mostrado de qué manera el proyecto no cambia en la exposición de Turín, el énfasis del discurso parece dirigirse a proyectar una imagen más exótica de la Amazonía y de sus habitantes en vista a su presentación a un público italiano, o en todo caso, no ecuatoriano. En este caso, en mi opinión, destaca más el aspecto etnográfico o espectacular de la exhibición, que deja finalmente en un segundo plano los aspectos civilizatorios, y pone más de relieve las dificultades encontradas en la recogida de los objetos, y en la vida en la misión en la Amazonía. En consecuencia, se puede observar la emergencia de la figura del misionero como héroe, y a veces como mártir, de manera acorde a cuanto estaba trasmitiendo la congregación a través de las páginas del Bollettino Salesiano. El hecho de destacar los sufrimientos de los misioneros servía además para sensibilizar respecto a las demandas de apoyo económico que se difundían a través de la misma publicación.

En fin, desde mi punto de vista, solo analizando en conjunto estas dos exposiciones se puede entender plenamente el discurso y el proyecto que los salesianos estaban desarrollando en la Amazonía ecuatoriana, en diálogo con las élites liberales del país andino y, más ideal que concretamente, con la comunidad católica mundial.

\section{FUENTES}

«All'Esposizione Missionaria Salesiana». 1926. Bollettino Salesiano 7 (luglio): 191-194.

Calcagno, Luigi. 1894. «Informe Misiones de Méndez y Gualaquiza dirigido al Ministro de la Instrucción Pública Roberto Espinosa, Quito, 5 de mayo de 1894». En Informe del Ministro de Instrucción pública, negocios eclesiásticos, justicia, beneficencia y caridad y estadística al Congreso Constitucional de 1894, Roberto Espinosa, 285-286. Quito: Imprenta del Gobierno.

Crespi, Carlo. 1924a. "Le meraviglie naturali dell'Equatore (Note di viaggio del missionario Don Carlo Crespi)». Bollettino Salesiano 3 (marzo): 68.
Crespi, Carlo. 1924b. "Gli indi della Sierra Equatoriana (Lettera del missionario salesiano Don Carlo Crespi)». Bollettino Salesiano 3 (marzo): 69-71.

Crespi, Carlo. 1924c. "XXX` anniversario della Missione di Gualaquiza (Lettera del missionario salesiano Don Carlo Crespi al sig. Don Rinaldi)». Bollettino Salesiano 5 (maggio): 123-125.

Crespi, Carlo. 1924d. «Un'esplorazione al Santiago (Lettera del Missionario Salesiano Don Carlo Crespi)». Bollettino Salesiano 10 (ottobre): 266-269.

Crespi, Carlo. 1924e. "Obra civilizadora en el Oriente azuayo». El Télegrafo, 27 de agosto.

Crespi, Carlo. 1925a. "Quaranta giorni di escursioni nella regione di Indanza (Relazione del Missionario Salesiano Don Carlo Crespi al Sig. Don Rinaldi)». Bollettino Salesiano 3 (marzo): 63-69.

Crespi, Carlo. 1925b. "Quaranta giorni di escursioni nella regione di Indanza (Relazione del Missionario Salesiano Don Carlo Crespi al Sig. Don Rinaldi)». Bollettino Salesiano 6 (giugno): 158-159.

«Da Gualaceo a Santiago di Méndez». 1920. Bollettino Salesiano 4 (aprile): 98-100.

«Esposizione Missionaria Salesiana. I selvaggi dell'Amazzoni». 1926. Momento, 5 settembre.

«Exposición etnográfica sobre los jíbaros del Oriente ecuatoriano». 1924. El Télegrafo, 6 de agosto.

«Exposición etnográfica de los jíbaros del Oriente». 1924. El Télegrafo, 17 de agosto.

«L'esposizione delle missioni salesiane». 1926. La Stampa, 29 aprile.

«La Real Nave Italia en Guayaquil». 1924. El Télegrafo, 5 de agosto.

«La solenne chiusura dell'Esposizione Missionaria salesiana». 1926. Bollettino Salesiano 11 (novembre): 284-293.

«Le curiosità dell'Esposizione delle Missioni Salesiane». 1926. La Stampa, 1 maggio.

Mattana, Francesco. 1897. "La vita che si vive in mezzo agli Jivaros (Dall'epistolario di D. Francesco Mattana)». Bollettino Salesiano 12 (dicembre): 312-317.

Mattana, Francesco. 1907. «Relazione del Superiore delle Missioni di Méndez e Gualaquiza al Capo Supremo della Repubblica». Bollettino Salesiano 2 (febbraio): 81-85.

«Mirajes al Oriente Ecuatoriano. Lo que vale esa gran porción de territorio patrio». 1924. El Universo, 4 de septiembre.

«Miremos hacia el Oriente. La exposición del Padre Crespi». 1924. El Universo, 24 de agosto.

\section{BibLIOGRAFÍA}

Anderson, Benedict. 1983. Imagined Communities. London - New York: Verso.

Brito, Elías. 1935. Homenaje del Ecuador a Don Bosco Santo. Tomo Primero. La obra salesiana en el Ecuador (1888-1935), Volumen destinado a conmemorar el cincuentenario del apostolado salesiano en el Ecuador. Quito: Escuela Tipográfica Salesiana.

Bottasso, Juan. 1982. Los Shuar y las Misiones. Entre la hostilidad y el diálogo. Quito: Mundo Shuar.

Bottasso, Juan (comp.). 1993. Los salesianos y la Amazonía. Tomo I. Actividades y presencia. Tomo II. Relatos de viajes (1893-1909). Tomo III. Relaciones etnográficas y geográficas. Quito: Abya-Yala.

Bottasso, Juan. 2011. Los salesianos y los shuar. Quito: Abya Yala.

Burke, Peter. 2001. Eyewitnessing. The Uses of Images as Historical Evidence. Londres: Reaktion Books Ltd.

Chartier, Roger. 1989. "Le monde comme représentation». Annales. Économies, Sociétés, Civilisations 44 (6): 1505-1520. https://doi. org/10.3406/ahess.1989.283667

Clark, Kim. 2004. La obra redentora. El ferrocarril y la nación en Ecuador 1895-1930. Quito: Universidad Andina Simón Bolívar Corporación Editora Nacional.

Coronel, Valeria y Mercedes Prieto (coords.). 2010. Celebraciones centenarias y negociaciones por la nación ecuatoriana. Quito: FLACSO, Sede Ecuador - Ministerio de Cultura. 
Esvertit Cobes, Natàlia. 2008. La Incipiente Provincia. Amazonía y Estado ecuatoriano en el siglo XIX. Quito: Universidad Andina Simón Bolívar - Corporación Editora Nacional.

Esvertit Cobes, Natàlia. 2014. "Los salesianos en el Vicariato Apostólico de Méndez y Gualaquiza». En La presencia salesiana en Ecuador. Perspectivas históricas y sociales, compilado por Lola Vázquez, Juan Fernando Regalado, Blas Garzón, Víctor Hugo Torres y José Juncosa, 471-512. Quito: Abya-Yala.

García Jordán, Pilar. 2015. "Los Chiriguanos en la Esposizione d’Arte Sacra e delle Missioni e delle Opere Cattoliche en Turín, 1898». En El mundo latinoamericano como representación, siglos XIX-XX editado por Pilar García Jordán, 81-106. Barcelona: Edicions UB TEIAA - IFEA.

Guarnieri Calò Carducci, Luigi. 2001. Dizionario storico-biografico degli italiani in Ecuador e in Bolivia. Bolonia: II Mulino.

Karsten, Rafael. 1935. The Head-hunters of Western Amazonas. The Life and Culture of the Jibaro Indians of Eastern Ecuador and Peru. Helsingfors: Societas Scientiarum Fennica.

López Ocón, Leoncio. 1998. "La América Latina en el escenario de las Exposiciones Universales del Siglo XIX». Procesos. Revista Ecuatoriana de Historia 18: 103-126. http://hdl.handle. net/10644/1600

Marin, Louis. 1993. Des pouvoirs des images. París: Éd. du Seuil.

Ministerio Coordinador de Desarrollo Social (ed.). 2008. Eloy Alfaro: pensamiento y políticas sociales. Quito: Cassolutions Publicidad.

Muratorio, Blanca. 1992. "Ensayo Introductorio: En la mirada de otro». En Retrato de la Amazonía. Ecuador 1880-1945, editado por Lucía Chiriboga, 13-27. Quito: Ediciones Libri Mundi - Enrique Grosse-Luemern.

Muratorio, Blanca. 1994a. «Introducción: Discursos y Silencios sobre el Indio en la Conciencia Nacional». En Imágenes e imagineros. Representaciones de los indígenas ecuatorianos, siglos XIX y XX, compilado por Blanca Muratori, 9-24. Quito: FLACSO.

Muratorio, Blanca. 1994b. «Nación, Identidad y Etnicidad: Imágenes de los Indios Ecuatorianos y sus Imagineros a Fines del Siglo XIX». En Imágenes e imagineros. Representaciones de los indígenas ecuatorianos, siglos XIX y XX, compilado por Blanca Muratori, 109. 196. Quito: FLACSO.

Pagnotta, Chiara. 2015. «Los salesianos y los jíbaros. Imágenes sobre el primer viaje de exploración al Oriente ecuatoriano (1893)». En El mundo latinoamericano como representación, siglos XIX-XX, editado por Pilar García Jordán, 157-176. Barcelona: Ediciones UB TEIAA - IFEA.

Pagnotta, Chiara. 2016. Situando los márgenes de la Nación. Los italianos en Ecuador (XIX-XX). Quito: ABYA-YALA - TEIAA.
Pagnotta, Chiara. 2017. «"Evangelizar” y “Civilizar” la Amazonía ecuatoriana. Una aproximación a la actividad del salesiano Carlo Crespi en la década de 1920». En La reinvención de América. Siglos XIX-XX, editado por Pilar García Jordán, 125-149. Barcelona: Edicions UB TEIAA.

Pagnotta, Chiara. 2018. «La Exposición Misional Vaticana de 1925, los misioneros salesianos y la representación del Oriente ecuatoriano". Procesos. Revista Ecuatoriana de Historia 47: 59-88. URL: http://hdl.handle.net/10644/6322

Pagnotta, Chiara. En prensa. «Ecuador, los inmigrantes y la propaganda fascista (1922-1938)». Revista de Indias.

Poole, Deborah. 1997. Vision, Race and Modernity. A Visual Economy of the Andean Image World. Princeton: Princeton University Press.

Pratt, Mary Louise. 2010. Ojos imperiales. Literatura de viajes y transculturación. México: Fondo de Cultura Económica.

Quintero, Rafael y Erika Silva. 2001. Ecuador: una Nación en Ciernes, Vol. I-II. Quito: Editorial Universitaria (Primera edición: FLACSO Abya-Yala, 1991).

Rivet, Paul. 1907-1908, «Les Indiens Jibaros. Etude géographique, historique et ethnographique». L'Anthropologie 18-19: 333-368

Sánchez Gómez, Luis Ángel. 2006. «Martirologio, etnología y espectáculo: la Exposición Misional Española de Barcelona (1929-1930)». Revista de Dialectología y Tradiciones Populares LXI (1): 63-102. https://doi.org/10.3989/rdtp.2006.v61.i1.3

Sánchez Gómez, Luis Ángel. 2011. «Imperialismo, fe y espectáculo: La participación de las Iglesias cristianas en las exposiciones coloniales y universales del siglo XIX». Hispania. Revista española de historia 237: 153-180. https://doi.org/10.3989/hispania.2011.v71. i237.339

Sánchez Gómez, Luis Ángel. 2013. Dominación, fe y espectáculo. Las exposiciones misionales y coloniales en la era del imperialismo moderno (1851-1958). Madrid: Consejo Superior de Investigación Científica.

Taylor, Anne-Christine. 1994a. «El Oriente ecuatoriano en el siglo XIX: "el otro litoral"». En Historia y región en el Ecuador: 18301930, compilado por Juan Maiguashca, 17-68. Quito: Corporación Editora Nacional.

Taylor, Anne-Christine. 1994b. «Una Categoría Irreducible en el Conjunto de la Naciones Indígenas: Los Jíbaros en las Representaciones Occidentales». En Imágenes e imagineros. Representaciones de los indígenas ecuatorianos, siglos XIX y XX, compilado por Blanca Muratorio, 75-107. Quito: FLACSO.

Vázquez, Lola, Juan Fernando Regalado, Blas Garzón, Víctor Hugo Torres y José Juncosa, comps. 2014. La presencia salesiana en Ecuador. Perspectivas históricas y sociales. Quito: Abya-Yala. 